\title{
Wilson Simonal: vida e morte de um superastro negro ${ }^{1}$
}

\author{
Carlos Eduardo Amaral de Paiva²
}

Resumo: Este texto analisa algumas passagens significativas da vida de Wilson Simonal. Sua carreira meteórica, bem como o esquecimento e o boicote de que foi vítima nos anos 1970 é tratado como um importante material para reflexão sociológica e artística. Como se sabe o envolvimento de Simonal com a ditadura militar nos anos 1960 acabou gerando uma polêmica que o afastou dos palcos. Neste artigo busco compreender como o mito da democracia racial e as relações de poder entre brancos e negros, no contexto ditatorial, nos oferecem um importante painel para elucidar como as relações étnicas podiam exercer influências sobre a posição de prestígio social, ao ponto de comprometer a carreira e todo o capital social de um artista promissor.

Palavras-chave: Wilson Simonal. Ditadura. Democracia racial.

\section{Wilson Simonal: Life and death of a black superstar}

Abstract: This text investigates only a few significant passages of Wilson Simonal's life. His meteoric career, as well as his oblivion and the boycott from which he was a victim in the 1970's are treated as an important material for sociologic reflection. The involvement of Simonal with the military dictatorship in the 1960s ended up generating a polemic that moved him away from the proscenium. In this article I seek to understand how the racial democracy myth and the power relations between black and white people in the dictatorial context offer us an important panel to elucidate the way ethnic relations could carry influence on social prestige position about to endanger the career and the social capital of a promising artist.

Keywords: Wilson Simonal. Dictatorship. Racial democracy.

\footnotetext{
${ }^{1}$ Recebido em 30/06/2017 e aprovado em 14/10/2017.

2 Prof. Dr. de Teoria Social do Instituto de Ciências Humanas e Sociais da Universidade Federal do Mato Grosso. Contato: du-paiva@hotmail.com.
} 
$|58|$

Wilson Simonal: vida e morte..

Wilson Simonal: vida y muerte de un superastro negro

Resume: Este texto analiza algunos pasajes significativos de la vida de Wilson Simonal. Su carrera meteórica, así como el olvido y el boicot de que fue víctima en los años 1970, es tratada como un importante material para la reflexión sociológica y artística. Como se sabe, la implicación de Simonal con la dictadura militar en los años 1960 acabó generando una polémica que lo alejó de los escenarios. En este artículo busco comprender cómo el mito de la democracia racial y las relaciones de poder entre blancos y negros, en el contexto dictatorial, nos ofrecen un importante panel para elucidar cómo las relaciones étnicas podían ejercer influencias sobre la posición de prestigio social, hasta el punto de comprometer la carrera y todo el capital social de un artista prometedor.

Palabras-clave: Wilson Simonal. Dictadura. Democracia racial.

Wilson Simonal pode ser considerado o primeiro grande superastro negro brasileiro. Sua carreira de sucesso meteórica, bem como seu esquecimento, é um dos casos mais intrigantes na cena musical brasileira. $\mathrm{O}$ cantor, que se envolveu com a ditadura civil militar nos anos 1970, sofreu um verdadeiro boicote da mídia e de seus pares, sendo relegado ao esquecimento e ao ostracismo até o fim da vida, no ano de 2001.

A história de Simonal nos oferece um bom parâmetro sobre os efeitos das relações de poder engendradas pelo estado de exceção em muitas carreiras artísticas. O golpe civil-militar de 1964 afetou também o campo artístico e musical, criando espaço para ascensão de artistas que, via de regra, não incomodavam o regime e censurando parte da esquerda. Por outro lado, a "relativa hegemonia cultural da esquerda" até fins dos anos 1960 garantia a inserção no mercado de bens simbólicos ${ }^{3}$ de artistas e produtores culturais progressistas contrários ao regime. Assim, dentro do disputado campo da música popular brasileira, as relações políticas e ideológicas influenciavam as posturas estéticas chegando a determinar gostos e a formar redes de relações que viriam a orientar carreiras artísticas, como no caso de Wilson Simonal.

${ }^{3}$ A respeito da hegemonia de esquerda no campo cultural, ver: Schwarz (2008); e Ridenti (2014). 
Existem diversas versões sobre vida de Simonal e o seu envolvimento com a ditadura civil-militar. A mais conhecida publicamente está no filme biográfico Ninguém sabe o duro que dei (2009), um documentário produzido pelos filhos do cantor, Wilson Simoninha e Max de Castro, que além de retratar o talento do músico, apresenta o ostracismo a que ele foi relegado. Outros dois livros: a biografia Nem Vem que Não Tem (2009) de Ricardo Alexandre e Simonal: Quem não tem swing morre com a boca cheia de formiga (2011), escrito pelo historiador Gustavo Alonso também investigam a carreira do cantor.

O trabalho de Gustavo Alonso, com o qual dialogo no presente artigo, discute a construção da imagem de Simonal bem como o apagamento do cantor na memória musical brasileira. $\mathrm{O}$ autor demonstra que a construção de uma memória de resistência heroica em torno da sigla MPB acabou isolando cantores não alinhados à esquerda, como Simonal.

Alonso nos apresenta uma história do campo da música popular, bem como da produção simbólica das esquerdas no país. Entretanto, o foco escolhido pelo autor acaba por deixar uma questão aberta. Qual foi o papel da imprensa não alinhada à esquerda e do próprio regime civil-militar no isolamento de Simonal? O historiador demonstra de maneira convincente como as "patrulhas ideológicas" da esquerda isolaram Simonal, mas não nos oferece muitas pistas sobre o papel da direita incrustada no regime ditatorial. Ora, como é sabido, Simonal alcançou o posto de garoto propaganda do regime militar, assim, o que teria causado o seu isolamento ou abandono por parte da imprensa e do próprio governo?

É esta questão que norteia o presente artigo, e para respondêla busco enfrentar o "caso Simonal" pela perspectiva étnico-racial e pela análise dos mecanismos ideológicos da democracia racial, fatores que influíram na construção de uma imagem desprestigiada do cantor.

Assim, acredito que não basta demonstrar que o Brasil é um país racista, é necessário também compreender os mecanismos sociais que engendram a hierarquia racial no país. 
Como demonstraremos no texto, embora o discurso oficial do regime militar buscasse negar o racismo no Brasil, este se agravou durante a ditadura. A violência institucional do regime de exceção tornava ainda mais rígidas as expectativas a respeito do comportamento e a posição na estrutura social dos indivíduos classificados como negros.

\section{Ascensão do mulato: os favores da democracia racial}

Wilson Simonal iniciou sua carreira em fins dos anos 1950, no chamado Clube do Rock, um programa televisivo comandado pelo polêmico produtor cultural Carlos Imperial. No programa, transmitido pela TV Tupi, apresentavam-se jovens cantores que viriam a ter uma carreira promissora como Roberto Carlos, Erasmo Carlos e Tim Maia. De maneira geral os músicos faziam covers de sucessos do rock internacional da época.

Com o fim do programa, Simonal passa a viver de "bicos" como crooner no então badalado Beco das Garrafas. O beco era conhecido como uma importante plataforma de lançamento de músicos brasileiros que juntavam a bossa nova com o jazz e apostavam em um estilo cool de se fazer música brasileira. Foi neste ambiente que Simonal conheceu Ronaldo Bôscoli, que viria a produzir o cantor e transformá-lo em uma verdadeira celebridade no mundo da música brasileira.

Seus primeiros dois discos, Wilson Simonal tem algo mais (1963) e A nova dimensão do samba (1964), embora tenham alcançado relativa aceitação do público, não se diferenciavam muito do gênero da bossa nova. Com regravações de importantes sucessos da época, o cantor buscava se inserir no campo musical, porém, sem muita inovação. Aproveitando sua potente voz e arranjos que combinavam o ritmo do samba com harmonias sofisticadas do jazz, a interpretação singular do cantor o destacava dentre os seus contemporâneos.

O início da carreira de Simonal reflete as transformações pelas quais passava o campo musical no Brasil da época. Se, por 
um lado, a chegada do rock criava uma cultura jovem vinculada à produção cultural internacional, por outro, o movimento da bossa nova, inaugurado em fins dos anos 1950, representava uma fase de produção cultural nacional, ainda que a bossa nova tenha gerado polêmicas devido às claras influências do jazz norte-americano. Esta produção cultural local irá se intensificar a partir de 1964 com o incentivo do regime militar para a formação de um mercado de bens simbólicos nacional.

Em fins dos anos 1960 Simonal era presença constante no famoso programa Fino da Bossa, comandado por Elis Regina e Jair Rodrigues. Como se sabe, o programa buscava uma valorização nacionalista da música popular seguindo um horizonte estético nacional-popular influenciado pela segunda geração da bossa nova. Assim, a música nacional vislumbrava certa ideia de povo brasileiro que, via de regra, era construída a partir de uma perspectiva mestiça.

A adesão de Simonal ao discurso mestiço nacionalista não impediu que o cantor experimentasse uma aproximação de temas que envolviam a afirmação de sua negritude. No ano de 1967, ainda como frequentador do Fino da Bossa, Simonal gravou sua famosa canção "Tributo a Martin Luther King"4. Trata-se de uma balada soul que apresenta elementos na letra e nos arranjos que entoavam a luta negra pelos direitos civis norte americano. Vejamos a letra da canção:

Sei sou negro de cor.

Meu irmão de minha cor

O que te peço é luta, sim luta mais

Que a luta está no fim.

Cada negro que for.

Mais um negro virá

Para lutar com sangue ou não

Com uma canção

${ }^{4}$ Canção gravada em: SIMONAL, Wilson. A Bossa e o balanço. São Paulo, Warner Music, 1994. CD. 
$|62|$

Wilson Simonal: vida e morte...

Também se luta irmão

Ouve minha voz, oh, yeah, luta por nós.

Luta negra é demais

É lutar pela paz luta negra é demais

Para sermos iguais.

Composta com Ronaldo Bôscoli, a canção tornou-se um clássico, sendo ainda hoje referência para o movimento negro brasileiro. Como podemos observar, a canção faz menção à luta pelos direitos civis dos negros norte-americanos, construindo uma irmandade de cor por meio da luta pelo reconhecimento étnico. Os arranjos de Cesar Mariano buscam assimilar uma balada soul com influências do swing. Segundo o biógrafo Ricardo Alexandre (2009), o próprio Simonal sugeriu que a música fosse swingada para tornar o tema mais leve.

"Tributo a Martin Luther King" foi tocada pela primeira vez na temporada de Mugnífico ${ }^{5}$ Simonal. Como era de se imaginar, a canção não foi bem recebida no contexto ditatorial, sendo detida pela censura e liberada somente depois de quatro meses de negociação e "explicação" dos autores. Simonal voltou a interpretar sua canção na TV Record em horário nobre na entrega do troféu Roquete Pinto em março de 1967 (cf. ALEXANDRE, 2009, p.101).

A afirmação de uma musicalidade negra está presente em outras canções de Simonal, entretanto, em "Tributo a Martin Luther King" o compositor associa uma letra sobre a luta negra a uma balada soul, o que pode ser considerado a primeira gravação de uma canção deste gênero no Brasil. Além disso, a canção é sintomática das lutas políticas dos negros norte americanos. Foi entre 1964-1967 que a luta por direitos civis nos Estados Unidos teve seus momentos mais tumultuados, mas também suas maiores vitórias, com a criação de uma legislação que

\footnotetext{
${ }^{5} \mathrm{O}$ show batizado como Mugnífico faz referência a um boneco de pano batizado de Mug, uma espécie de amuleto que Simonal e outros artistas usavam.
} 
passava a proibir a discriminação racial nas relações trabalhistas e nas eleições (PURDY, 2011, p. 246).

É significativo que este discurso étnico venha dos EUA, como assinala Stuart Hall (2003). Em meados dos anos 1960 houve uma importante mudança na conjuntura global que deslocou o eixo de produção e propagação cultural da Europa para os EUA. Neste contexto, a ideia de etnia começa a ganhar força, já que a cultura europeia pouco se definiu como étnica, diferente das políticas culturais norte americanas, em que a questão da etnicidade sempre esteve presente. Assim, as influências cada vez maiores da cultura norte-americana sobre a produção cultural brasileira auxiliaram na formulação de modelos de identidade étnica entre parte significativa dos negros brasileiros.

Como nos lembra Gustavo Alonso (2011) “Tributo a Martin Luther King" nunca chegou a ser considerada uma canção de protesto pela historiografia da música popular brasileira. Para o autor, a acusação de "dedo duro" que caiu sobre Simonal tendeu a apagar um lado mais ativista do cantor. Entretanto, é importante ressaltar, conforme aponta o próprio Alonso, que Simonal não se enquadrava no modelo combativo da luta pelos direitos civis. O cantor pregava uma integração racial pacífica, como viria a afirmar:

Eu posso contestar, mas de maneira suave. Era assim quando cantava "Tributo a Martin Luther King". Eu posso denunciar, mas de maneira amigável, porque sou contra a violência, contra a provocação. Eu acho que na milonga [no jeitinho, na conversa, de forma pacífica] a gente consegue o que quer (Wilson Simonal apud ALONSO, 2011, p. 88).

Por meio desta declaração podemos observar como o discurso sobre a luta dos direitos civis nos EUA foi incorporado a uma matriz ideológica brasileira. As ideias de luta pela igualdade étnico-racial foram aclimatadas e reelaboradas por Simonal quando afirma: "Eu acho que na milonga a gente consegue o que quer". O cantor afirma sua preferência pela negação dos conflitos. 
Desta forma, mesmo que se referindo à luta dos negros norteamericanos, a contestação de Simonal é brasileira, relacionando-se a uma lógica do favor e à negociação de direitos. Ainda que realce a luta internacional negra, o autor recorre a uma matriz nacional de sociabilidade como forma de conciliação de conflitos.

Muito embora a declaração de Simonal reflita uma postura política, outra leitura é possível. Como observamos, a canção foi censurada por quatro meses pela ditadura devido o seu caráter político. Assim, é possível que as explicações de Simonal que sua contestação seria suave, amigável e não provocativa, refletissem na verdade uma forma de não se envolver com as questões políticas da ditadura.

É importante ressaltar que durante a ditadura civilmilitar as questões étnico-raciais também foram censuradas, os censores argumentavam que os únicos problemas raciais do Brasil provinham dos que afirmavam terem problemas (SKIDMORE, 1994, p. 13). Assim, as questões raciais eram deslegitimadas e qualquer denuncia de racismo no país era tratada como uma ideologia alienígena, implantada por "agitadores" influenciados por movimentos subversivos internacionais. Tal perspectiva ia ao encontro da política de integração nacional do regime militar, que se esforçava em construir uma ideia harmoniosa de nação em todos os setores da sociedade, inclusive nas relações étnico-raciais. Neste contexto, uma canção como "Tributo a Martin Luther King", que homenageava um líder negro estrangeiro e se remetia à luta negra norte-americana, só poderia ser vista com desconfiança pelos censores da ditadura.

A censura da canção indica uma ambiguidade entre as influências da luta negra internacional e a construção de uma brasilidade mestiça. Como sabemos, Simonal optou pela matriz brasileira de identidade nacional, seguindo o elogio da mestiçagem e das singularidades do hibridismo, o que lhe serviu como importante plataforma de prestígio social na mídia e também nas esferas do poder oficial. 
O grande momento da carreira do superastro foi sua famosa apresentação no Maracanãzinho em 1969. Simonal fora convidado, junto com outros cantores, para uma pequena apresentação que antecederia o show principal de Sergio Mendes, entretanto, o cantor conseguiu empolgar a plateia de tal forma que sua saída do palco foi quase impossível. A respeito do show, o Jornal do Brasil deu a seguinte nota:

Wilson Simonal, o dono da noite, foi um capítulo a parte. É o maior fenômeno de comunicação do momento, no Brasil. Simonal diz duas frases, o resto o público canta. Foi impressionante. É um cantor que brinca com a voz, ora imposta, ora a deixa na garganta, em um som metálico semelhante a um instrumento. [...] O público quase esqueceu Sergio Mendes, para ouvir Simonal. Em termos de popularidade, foi a consagração do cantor .

Depois da consagração o cantor se tornou um verdadeiro superastro. Mais que um artista, Simonal transformou-se em uma marca altamente comerciável. Suas apresentações na TV eram cada vez mais constantes, jornais e revistas apresentavam longas entrevistas e reportagens sobre sua história de vida, narrando a trajetória do menino negro e pobre que venceu na vida.

Patrocinado pela multinacional Shell, Simonal representava ainda uma imagem de simpatia e malandragem condizente à valorização de nossa mestiçagem racial. Explorando arranjos musicais que fundiam jazz, bossa nova e samba, o cantor construiu uma imagem mestiça inclusive em suas influências sonoras.

Uma das canções mais emblemáticas que representam esse clima de brasilidade mulata é a famosa "País tropical", composta por Jorge Ben ${ }^{7}$. A análise da canção pode nos oferecer um bom

${ }^{6}$ Cf. "Maracanãzinho: termômetro musical”, Jornal do Brasil, Caderno B, Rio de Janeiro, 14 jul. 1969, p. 2.

7 Canção gravada em: SIMONAL, Wilson. Alegria, alegria. Rio de Janeiro, 
|66 |

Wilson Simonal: vida e morte...

panorama sobre a imagem que Simonal buscou construir sobre si e sobre o Brasil. Vejamos a letra:

Moro num país tropical, abençoado por Deus

E bonito por natureza, mas que beleza

Em fevereiro (em fevereiro)

Tem carnaval (tem carnaval)

Tenho um fusca e um violão

Sou Flamengo

Tenho uma nêga

Chamada Tereza

Sambaby

Sambaby

Sou um menino de mentalidade mediana

Pois é, mas assim mesmo sou feliz da vida

Pois eu não devo nada a ninguém

Pois é, pois eu sou feliz

Muito feliz comigo mesmo

Moro num país tropical, abençoado por Deus

E bonito por natureza, mas que beleza

Em fevereiro (em fevereiro)

Tem carnaval (tem carnaval)

Tenho um fusca e um violão

Sou Flamengo

Tenho uma nêga

Chamada Tereza

Sambaby

Sambaby

EMI-Odeon, 1969. LP. 


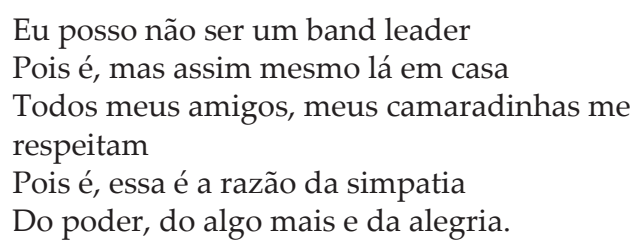

A canção fazia coro ao otimismo que o regime militar buscava transmitir para a sociedade brasileira. Um menino de mentalidade mediana que vive em um país de beleza estonteante, sempre simpático com seu fusca e seu violão. Enquanto o violão é representativo da mestiçagem brasileira, o fusca simboliza o poder aquisitivo alcançado pela classe média com o milagre econômico. Se com "Tributo a Martin Luther King" Simonal desagradava os militares, com "País Tropical", o músico fazia as pazes com o regime e tornava-se o garoto propaganda de certa imagem otimista, simpática e mestiça do Brasil.

A imagem simpática de Simonal é expressa com maestria em "País Tropical". Aqui a simpatia não se limita a uma expressão do cantor, mas adentra na própria estrutura da ideia de brasileiro como homem cordial. Na famosa expressão de Sergio Buarque de Holanda (1995), a cordialidade pode ser definida como uma dificuldade do brasileiro em diferenciar o espaço público do privado, o que acarreta um abuso da pessoalidade nas regras de trato social. Não adaptado às regras de impessoalidade das sociedades modernas, o homem cordial, que "pensa com o coração", é expansivo em sua emotividade e pouco afeito ao impessoalismo exigido nas relações sociais dentro da esfera pública. Assim, a simpatia é expressão desta cordialidade expansiva nas regras de trato.

Se a letra da canção em si já traz uma forte dose dessa cordialidade, a interpretação de Wilson Simonal, bem como as mudanças da letra operadas pelo intérprete, apresentava esse caráter cordial do homem brasileiro de maneira ainda mais incisiva. Acontece que o cantor literalmente inventa uma nova 
língua dentro da canção, retirando as últimas sílabas das palavras e mudando completamente as orações. Assim a frase "Moro num país tropical", com Simonal se transformava em "Mo...num pá... tropi", "Abençoado por deus" tornava-se "Abençoa por de", e "E bonito por natureza" virava "E boni...por nature..". É interessante notar que o intérprete mantinha a pontuação dos tempos fortes, o que não prejudicava em nada a métrica da canção, além disso, ainda que "camuflando" a letra, esta não deixava de ser compreendida pelo público, ao contrário, a expressão "patropi" se difundiu na época como sinônimo de Brasil (cf. ALEXANDRE, 2009, p.145).

Essas mudanças nas palavras revelam também algo bem típico do caráter cordial. Sérgio Buarque observa que no Brasil há uma tendência à aproximação por meio de uma suavização vocabular. Assim, é comum que se use o sufixo "inho" como diminutivo para denotar uma maior proximidade nas formas de trato. Ao suprimir as últimas sílabas das palavras da canção, Simonal opera com uma redução morfológica para compor novas palavras que sugerem também uma maior aproximação no trato. Desse modo, o cantor criava um dialeto em formas de gírias que conseguiam traduzir uma visão cordial e simpática de Brasil como um país tropical. Outra mudança na letra foi o uso da expressão "algo mais", acrescentada por Simonal. A expressão era o slogan da Shell, empresa com quem o cantor negociava sua contratação como garoto propaganda (ALEXANDRE, 2009, p. 145).

Alçado ao posto de garoto propaganda do otimismo brasileiro, Simonal tornou-se uma espécie de embaixador informal do Brasil. Além de acompanhar a seleção brasileira na copa do México de 1970, o cantor também serviu como representante do V Festival Internacional da Canção (FIC) no mesmo ano, produzido pela Rede Globo de Televisão em parceria com a Shell e a secretaria de turismo do Rio de Janeiro. Como se sabe, o evento televisivo internacional servia como um importante instrumento de promoção do regime civil-militar, buscando revelar para o mundo a produção musical brasileira e nossa suposta hospitalidade. 
Seu disco gravado para o lançamento do V FIC é um verdadeiro elogio ao nacionalismo ufanista do regime militar, representado por duas canções: "Cada um cumpra com o seu dever" e "Brasil eu fico" ${ }^{\prime \prime}$. As canções musicavam famosos slogans da ditadura, servindo não só como promoção do festival como também do próprio regime. "Cada um cumpra com o seu dever" convocava todos os setores da nação a cumprir com o seu dever para o desenvolvimento do país, enquanto "Brasil eu fico" inicia conclamando os diferentes estados do país para seguir no seguinte refrão:

\author{
Este é o meu Brasil, \\ Cheia de riquezas mil \\ Este é o meu Brasil \\ Futuro e progresso do ano dois mil \\ E quem não gostar ou for do contra \\ Que vá pra...
}

A música faz uma referência positiva ao slogan "Brasil, ame ou deixe-o". Seguindo o direcionamento moralista do regime há um efeito de sugestão do palavreado de baixo calão "puta que o pariu", amenizando o processo de extradição pelo qual passavam os militantes de esquerda no país.

$O$ regime militar investia em publicidade para criar uma imagem de apaziguamento e otimismo no país. Neste contexto, as canções promocionais do V FIC buscavam retratar este otimismo, apresentando o Brasil como um país em processo de desenvolvimento e harmonia social. Como embaixador do $\mathrm{V}$ FIC, Simonal se apresentou no MIDEM na França, um dos maiores eventos da indústria fonográfica mundial. $\mathrm{O}$ cantor ainda faria um especial para a televisão italiana e um show comemorativo da televisão portuguesa em Lisboa (cf. ALEXANDRE, 2009,

\footnotetext{
8 Canções gravadas em: SIMONAL, Wilson. V Festival Internacional da Canção. Rede Globo: homenagem da Shell Brasil. Rio de Janeiro, EMI-Odeon, 1970. EP.
} 
p.157). Assim, a imagem carismática de Simonal promovia o festival pela Europa, levando também certa imagem descontraída, otimista e simpática de brasilidade.

Como podemos observar, durante os anos 1960 Simonal era reconhecido como um importante astro da música brasileira, apadrinhado pelos poderosos do regime civil-militar e pela grande mídia. Cabe agora questionar o que teria ocorrido para o seu apagamento. Como um artista tão prestigiado pelos que detinham o poder foi, da noite para o dia, não apenas esquecido pela imprensa como também perseguido por seus pares? Uma análise das configurações de poder construídas no contexto da ditadura pode nos auxiliar a responder esta questão. Buscaremos compreender como a biografia do cantor e sua posição de artista e negro se entrecruzam com as relações de poder estabelecidas durante o estado de exceção brasileiro.

\section{O outro lado da democracia racial}

No início dos anos 1970 a carreira de Simonal sofreu uma verdadeira reviravolta que lhe custou o ostracismo e a alcunha de "dedo-duro". O caso se deu após um desentendimento com o seu contador. O cantor, que possuía amigos no Departamento de Ordem Política e Social (DOPs), teria pedido aos policiais que inquirissem seu contador a fim de que ele confessasse que estava roubando o músico. $\mathrm{O}$ inquérito truculento dos policiais acabou de maneira violenta com a tortura do funcionário. $\mathrm{O}$ ocorrido foi amplamente divulgado pela imprensa e acabou associando Simonal aos delatores da ditadura, afastando o cantor dos programas musicais e criando uma imagem extremamente depreciativa do cantor.

O envolvimento de Simonal com a ditadura e a acusação de delator que caiu sobre ele afetou diretamente sua carreira. Apesar de se dizer a favor do regime, Simonal não era ativista; sua relação com os militares, como observamos, era uma relação 
de troca de favores, o regime se utilizava de sua fama assim como o artista aproveitava as redes de relações possibilitadas pela sua posição conveniente ao regime militar. Entretanto, o uso da força militar para tramar uma conspiração contra seu contador parece ter surtido um efeito extremamente negativo. O problema é que não sendo um militar, Simonal foi acusado judicialmente de uso particular da máquina pública e o evento "alcançou caráter de polêmica".

A campanha deflagrada pelo jornal O Pasquim contra o cantor é representativa da insinuação que recaiu sobre ele, o jornal apresentava em uma de suas páginas um dedo em riste como o nome Simonal, aludindo à alcunha de alcaguete (ARAÚJO, 2010, p. 290). Com a acusação o jornal buscava criar uma polêmica em torno do caso. Como se sabe, o semanário era um dos poucos veículos da imprensa abertamente de oposição e não economizava nas tintas ao ridicularizar os apoiadores do regime militar.

Em fins de 1971 o maestro Julio Hungria denunciava o boicote pelo qual passava Simonal:

\begin{abstract}
Recentemente, no Brasil, uma série de emissoras ignorou, por várias semanas, os discos de Wilson Simonal. A par da validade dos motivos e das virtudes ou pecados que se acumulam em maior ou menor dose num artista ou numa atitude, o boicote será, sempre no mínimo, falta de respeito para com o compromisso geral que o veículo assume com o público e que está acima dos problemas e vaidades, eventuais e transitórias ${ }^{9}$.
\end{abstract}

Em 1972 a carreira de Simonal já estava comprometida, boicotado pela mídia e isolado no campo artístico, Simonal passou ao ostracismo; suas parcas apresentações públicas eram recebidas com vaias ou simplesmente ignoradas. O Jornal do Brasil, que até então era um dos grandes propagandistas da imagem

${ }^{9}$ Cf. HUNGRIA, Júlio. "Boicote", Jornal do Brasil, Caderno B, Rio de Janeiro, 12 out. 1971, p. 2. 
$|72|$

Wilson Simonal: vida e morte...

do superastro, apresentava da seguinte maneira a drástica transformação do artista.

O sorriso fácil de quem sabe, antes de entrar no palco, que a parada está ganha; as reportagens de muitas páginas nos jornais e revistas; a trupe que o seguia em busca de favores e promoção, nada disso existe mais para Wilson Simonal, o homem que conquistou o Maracanãzinho roubando o show de Sergio Mendes ${ }^{10}$.

A nota do jornal é representativa do final da carreira de Simonal. Acusado de delator, o cantor foi relegado ao ostracismo em menos de dois anos. Desprestigiado, Simonal perdia seu capital social, deixava de ser apadrinhado e se isolava cada vez mais.

Não há como negar a relação entre Simonal e a ditadura, entretanto, não se sabe ao certo qual a sua real influência. Apesar de seu apoio à ditadura, o cantor não fazia parte do regime, usou o regime civil militar em seu próprio benefício e pagou caro por isso. Porém, é pouco provável que tenha servido às forças militares como delator de artistas comunistas.

Mais interessante do que nos atermos ao quanto Simonal se envolveu com o governo militar é nos questionarmos os parâmetros que construíram a imagem do cantor como delator. Afinal, outros cantores de prestígio também foram acusados de delatores. Teria Simonal servido como bode expiatório no meio musical? Ou o fato de ser um negro com uma carreira meteórica teria lhe custado a alcunha de dedo-duro?

É fato que Simonal nunca teve apoio da esquerda, a campanha contra o cantor e o boicote costumam ser explicados como uma perseguição das chamadas "patrulhas ideológicas". Tal perspectiva nos parece parcialmente verdadeira; muito embora a esquerda brasileira tivesse relativa hegemonia no campo

${ }^{10}$ Cf. "Agora um outro Simonal", Jornal do Brasil, Caderno 2, Rio de Janeiro, 22 set. 1972 , p. 1. 
cultural, a sistematização da indústria cultural no país começava a minar essa hegemonia. A lógica empresarial no campo cultural podia comercializar tanto o discurso da esquerda, representada pela MPB nacionalista, quanto as canções que não tinham nenhum compromisso político. Embora a campanha deflagrada pelo Pasquim tenha iniciado o processo de escárnio contra o cantor, acredito que a manutenção desta campanha e o isolamento social de Simonal podem ser mais bem compreendidos a partir de uma análise das relações raciais no Brasil dos anos 1960/1970, bem como da visão que a mídia e a opinião pública tinham a respeito do negro na sociedade brasileira.

Dentre os diversos relatos sobre Wilson Simonal, uma característica do cantor é sempre ressaltada, sua arrogância e ostentação. $\mathrm{O}$ cantor também não possuía nenhum pudor em confessar o seu comercialismo e aquilo que ele mesmo definia como "pilantragem". A ostentação e a arrogância de Simonal são relatadas pelo produtor Nelson Motta:

Quanto mais sucesso fazia, mais arrogante se tornava,
mais vaidoso, mais autossuficiente, e mais gente tinha
à sua volta. No palco, era divertidíssimo, o público
o adorava, mas na vida real cada vez mais gente
o detestava pelas costas (MOTTA, 2000, p. 126).

Em uma matéria especial de cinco páginas no Jornal do Brasil, o próprio Simonal confessava sua fama de antipático:

[...] o que aconteceu é que eu criei fama de antipático e até hoje tem gente que diz que sou 'banqueiro' só porque não faço o tipo marginal. Por quê? Porque a imagem do negro é aquele tipo marginal. Preto tem que ficar tocando pandeiro, caixa de fósforo, ficar fazendo palhaçada no palco. Como eu faço um gênero que o pessoal acha que é gênero de branco, então dizem que fiquei pretensioso, sou metido a importante. Isto é uma consequência do preconceito 

coisas todas ${ }^{11}$.

Pela sua fala nota-se que o cantor possuía relativa consciência de sua condição de negro em uma sociedade hierarquicamente racializada. Simonal expõe a tentativa de folclorização do negro e o enquadramento de seu comportamento como tipicamente branco.

Assim, o superastro não se enquadrava na imagem de negro humilde e subserviente correspondente às expectativas da opinião pública. Ou seja, diferente das expectativas sociais a respeito de um negro originário das camadas populares, Simonal era "um negro que não sabia o seu lugar". Como bem demonstrou Emilia Viotti Costa (1999), a democracia racial no Brasil enfatiza um discurso em que é permitida relativa ascensão social do negro, desde que este adote os padrões sociais brancos e "saiba o seu lugar" por meio de regras subjetivas de comportamento. Assim, o estilo de vida adotado por Wilson Simonal e seu prestígio social não se adequavam à visão hierárquica sobre o lugar do negro na sociedade brasileira.

$\mathrm{O}$ estudo comparativo entre as relações raciais no Brasil e nos EUA, feito por Oracy Nogueira (1985), pode ser particularmente útil para compreendermos como Simonal lidou com a ambiguidade entre sua posição de prestígio social e a negritude. Como demonstra o sociólogo, o tipo de preconceito no Brasil é diferente do preconceito dos EUA. Enquanto neste último prevalece um "preconceito de origem", na chamada one-drope rule, em que um descendente negro é suficiente para categorizar o indivíduo como negro, no Brasil o preconceito racial se baseia na marca ou na aparência, não na ascendência. Assim, a questão racial no Brasil é relacional, o indivíduo negro pode ou não ser identificado como pertencente

${ }^{11}$ Cf. Wilson Simonal. In: "Simonal: eu sou um deles", Jornal do Brasil, Caderno B, Rio de Janeiro, 2 fev. 1970, p. 10. 
ao grupo negro de acordo com seu status e poder econômico. Pode ainda ser aceito dentro de certos círculos de acordo com o seu prestígio, ou seja, no Brasil desenvolveu-se um sistema social de coloração.

Oracy Nogueira observa que o preconceito de origem, presente nos EUA, "leva à retenção no grupo racial oprimido de seus membros mais bem-sucedidos" (NOGUEIRA, 1985, p. 23) e consequentemente forma um patrimônio cultural distinto neste grupo. Já o preconceito de marca, tal como existe no Brasil, tende a direcionar os grupos raciais oprimidos à incorporação dos valores dos grupos raciais hegemônicos por meio da miscigenação. Esses dois tipos de preconceitos têm suas consequências políticas na formação de identidades étnicas mais coesas entre os grupos raciais oprimidos que sofrem o preconceito de origem, tais como nos EUA. No Brasil o grupo classificado como negro tende a se adaptar à ideologia mestiça ou formar um grupo outsider pouco coeso.

É interessante notar como o próprio Simonal elaborava a sua condição de superastro negro. Quando questionado sobre o racismo no Brasil, Simonal afirmava: "Eu tive mil problemas porque era preto, antes de fazer sucesso. Não tenho agora porque sou rico, os meus problemas já são outros. Há uma frase que define bem o que eu penso: em lugar em que preto não entra, pobre também não entra" (ALONSO, 2011, p. 85).

$\mathrm{O}$ cantor parece ter consciência do caráter relacional das formas de classificação raciais no Brasil, ou seja, as marcas de prestígio tais como a fama e o dinheiro tendem a incorporar o indivíduo ao grupo branco, enquanto os status negativos se concentram nos grupos negros. É justamente por isto que a aceitação do negro no grupo dominante passa por um maior controle de suas ações, bem como um ajustamento destas às expectativas do grupo branco hegemônico.

Ainda que o fator econômico seja um dos principais elementos de prestígio social, a aparência que aciona o "preconceito de marca" funciona como um fator constrangedor e de incoerência 
no status social. Dentro da lógica da democracia racial brasileira a aceitação do superastro negro passava por uma adequação às ordens e às expectativas sociais da opinião pública.

O caso de Simonal é revelador deste sistema relacional proporcionado pela democracia racial brasileira. Outro episódio nos oferece um parâmetro a respeito de suas posições políticas e sua identidade racial: a jornalista Lea Penteado relata que certa vez, meses depois da polêmica com o DOPS, o cantor se encontrava em um restaurante e notou que alguns jornalistas presentes no mesmo recinto riam e o hostilizavam. Irritado com as provocações, Simonal respondia: "a diferença entre nós é que eu sou um negro rico, e não tenho compromisso com a esquerda nem com a direita" (Wilson Simonal apud PENTEADO, 1993, p. 131).

Simonal acionava sua condição material para justificar seu posicionamento político, deixando transparecer que seu status econômico lhe dava sustentação e prestígio suficientes para contrabalancear sua condição étnica e seu posicionamento político.

Apesar de acionar sua fama e sua condição material para menosprezar aqueles que o provocavam, a verdade é que o cantor estava isolado. Não podia contar com o apoio dos músicos e intelectuais da esquerda, tampouco podia contar com o apoio da mídia, que representando a opinião pública viam agora Simonal como um "negro arrogante", portanto, fora dos padrões esperados pela elite branca e pela ideologia da democracia racial.

Em 1975, Simonal tenta uma última aproximação com seu antigo público. Convidado para comemoração de dez anos do Beco das Garrafas, a apresentação do cantor foi frustrada pela plateia. Como relata Nelson Motta:

Eis que começa o show. No palco Wilson Simonal - um cara que cometeu muitos equívocos e erros, desacertos, calhordices e passou o diabo nos últimos tempos - lutando para sobrevier no seu ofício, que, diga-se de passagem, pelo menos tecnicamente, exerce com competência. Ouve-se um berro na seleta plateia: "negro (impublicável)". E depois outros, sempre 
do mesmo indignado e "intransigente" defensor da integridade e do caráter das pessoas... ${ }^{12}$.

A passagem é reveladora do esgotamento do prestígio social de Simonal. Foi nessa dissolução que a imagem do superastro simpático e representante de nossa democracia racial se transfigurou em uma imagem do negro arrogante que "não sabe o seu lugar".

É importante observar que simpatia e arrogância se configuram como dois lados da mesma cordialidade brasileira. $\mathrm{O}$ arrogante, assim como o simpático, apresenta na epiderme uma extensão de sua vida privada e, fazendo parte da mesma estirpe do homem cordial, possui uma imensa dificuldade em reconhecer a igualdade impessoal nas regras de trato precipitando uma hierarquização nas relações sociais. O problema é que dentro da democracia racial as expectativas sociais sobre o negro, mesmo quando figura reconhecidamente pública, é que seja sempre simpático e nunca arrogante.

A análise de Roberto DaMatta (1987) sobre as relações raciais brasileiras pode ser particularmente útil para compreendermos a trajetória de Simonal. Como afirma o antropólogo a sociedade brasileira, dada a sua hierarquização autoritária, é uma sociedade onde cada um sabe o seu lugar num sistema orientado verticalmente. Em um sistema hierarquizado desta forma, a discriminação só ocorre com aquele que se encontra incongruente com seu lugar. No contexto social brasileiro, as pessoas-alvo de discriminação são aquelas que se encontram fora das redes de relações construídas e legitimadas.

Assim, dentro do sistema relacional de coloração já explicitado por Oracy Nogueira, DaMatta (1987) assinala que indivíduos afro-brasileiros podem ser mais ou menos enegrecidos de acordo com o contexto e com a conformidade ou não das expectativas sociais e normas de condutas.

${ }^{12}$ Cf. MOTTA, Nelson. “De Boca Cheia”, O Globo, Rio de Janeiro, 21 out. 1975, p. 35. 
$|78|$

Wilson Simonal: vida e morte...

Tal fenômeno pode ser observado pela metamorfose da imagem de Simonal. Enquanto estava no auge da fama, e podia contar com uma extensa rede de relações, o superastro representava a simpatia brasileira e a nossa malandragem (ou "pilantragem", nos termos do próprio cantor). Uma vez envolvido em um escândalo, a simpatia transformava-se em arrogância e a malandragem dava lugar ao dedo-duro. Uma mudança do polo positivo do mestiço integrado ao polo negativo representado pelo negro que "não sabe o seu lugar".

O episódio demonstra como Simonal viveu a contradição de ser um negro rico no mundo dos brancos. Não correspondendo às expectativas sociais sobre o negro no Brasil, o cantor perdia também sua rede de relações, seu capital social, que no Brasil se configura como o principal tipo de capital para a manutenção do prestígio social. Sua transformação social em um delator do regime acompanhou a imagem e a própria cor do superastro. $\mathrm{O}$ dano ao seu prestígio foi seguido por um processo de enegrecimento de sua imagem. Ou seja, a perda de carisma e status de superastro foi acompanhada de uma classificação racial, Simonal deixava de ser o mulato simpático para tornar-se o negro arrogante.

O caso de Simonal é sintomático da forma como se estruturaram as relações étnico-raciais no Brasil durante a ditadura. Busquei enfatizar como o cantor viveu dois lados da democracia racial, de um lado a fama e o prestígio vinculados à perspectiva mestiça e simpática, de outro a marginalização e o emudecimento acompanhados pela construção de uma imagem outsider do compositor.

Para Antonio Sérgio Guimarães (2004) a democracia racial teve seu fundamento durante as décadas de 1930-1960, quando parte da intelectualidade brasileira e da militância negra acreditavam sinceramente na convivência harmoniosa entre pessoas de diferentes cores, credos e crenças. O golpe de 1964 representou o fim deste pacto. Como afirma o autor: 


\begin{abstract}
A partir desse momento, a democracia racial já não serve nem mesmo como ideal ou inspiração: não por acaso, a luta contemporânea dos negros pelos direitos sociais inerentes à democracia brasileira passou a ter como mote a luta por cidadania e respeito aos direitos humanos (GUIMARÃES, 2004, p. 23).
\end{abstract}

Embora concorde com a perspectiva de Guimarães, acredito que o fim do pacto entre classes, e incluo aqui entre raças e etnias, balizado pelo golpe militar, fez surgir de maneira ainda mais incisiva um lado obscuro da democracia racial. O que termina com o golpe militar é a democracia racial como pacto conciliatório construído idealmente, entretanto, no plano político a ideia de democracia racial torna-se ideologia oficial do regime. Nesta perspectiva a democracia racial transfigura-se de utopia em ideologia, para usar os termos de Mannheim ${ }^{13}$; ou seja, de utopia de uma sociedade sem conflitos para ideologia oficial de mascaramento dos conflitos étnico-raciais.

É neste contexto que podemos compreender o silenciamento e o execramento público de Simonal. O autoritarismo do regime de exceção realçou ainda mais as estruturas hierárquicas verticais, e como assinala DaMatta (1987) o lugar para cada coisa e, complementarmente, cada coisa em seu lugar. Em tal situação Simonal tornava-se um negro fora do seu lugar. Destituído de seu de carisma, o antigo superastro da democracia racial tornavase um negro arrogante, fora do padrão de resistência apregoado pela esquerda, mas também excluído da ideologia oficial que outrora lhe oferecera suporte, fama e prestígio.

13 Embora os termos de Mannheim possam ser usados para pensar a democracia racial brasileira, uso aqui de maneira ilustrativa e metafórica, sem a conotação da teoria do conhecimento desenvolvida pelo autor. 
$|80|$

Wilson Simonal: vida e morte...

\section{Referências}

ALEXANDRE, Ricardo. Nem vem que não tem: A vida e o veneno de Wilson Simonal. São Paulo: Globo, 2009.

ALONSO, Gustavo. Simonal: Quem não tem swing morro com a boca cheia de formiga. Rio de Janeiro: Editora Record, 2011.

ARAÚJO, Paulo Cesar. Eu não sou cachorro não: música popular cafona e ditadura. $7^{a}$ Edição. Rio de Janeiro: Record, 2010.

BOURDIEU, Pierre. Razões práticas: sobre a teoria da ação. Campinas: Papirus, 1997.

COSTA, Emília Viotti. Da monarquia à república: momentos decisivos. São Paulo: Ed. UNESP, 1999.

DAMATTA, Roberto. Relativizando: Uma introdução à antropologia social. Rio de Janeiro: Rocco, 1987.

ELIAS, Norbert. Os estabelecidos e os outsiders: sociologia das relações de poder a partir de uma pequena comunidade. Rio de Janeiro: Zahar, 2000.

FICO, Carlos. Reinventando o otimismo: Ditadura, propaganda e imaginário no Brasil. Rio de Janeiro: Fundação Getúlio Vargas, 1997.

GUIMARAES, Antonio Sérgio Alfredo. Preconceito de cor e racismo no Brasil. Rev. Antropol., São Paulo, v. 47, n. 1, p. 9-43, 2004.

GUIMARÃES, Antonio Sérgio. Democracia racial: o ideal, o pacto e o mito. Novos Estudos Cebrap, XX (61): 147-162. São Paulo, 2001.

HALL, Stuart. Da diáspora: identidades e mediações culturais. Belo Horizonte: UFMG, 2003.

HOLANDA, Sérgio Buarque. Raízes do Brasil. 26ª Edição, São Paulo: Companhia das Letras, 1995. 
MOTTA, Nelson. Noites tropicais: improvisos e memórias musicais. Rio de Janeiro: Objetiva, 2000.

NOGUEIRA, Oracy. Tanto preto quanto branco: Estudos de relações raciais. São Paulo: T. A. Queiroz, 1985.

PENTEADO, Lea. Um instante, maestro!. Rio de Janeiro: Record,1993.

SKIDMORE, Thomas. O Brasil visto de fora. Rio de Janeiro: Paz e Terra, 1994.

\section{Fontes jornalísticas}

"Agora um outro Simonal", Jornal do Brasil, Caderno 2, Rio de Janeiro, 22 set. 1972, p. 1.

HUNGRIA, Júlio. "Boicote”, Jornal do Brasil, Caderno B, Rio de Janeiro, 12 out. 1971, p. 2.

"Maracanãzinho: termômetro musical", Jornal do Brasil, Caderno B, Rio de Janeiro, 14 jul. 1969, p. 2.

MOTTA, Nelson. "De Boca Cheia", O Globo, Rio de Janeiro, 21 out. 1975, p. 35.

"Simonal: eu sou um deles", Jornal do Brasil, Caderno B, Rio de Janeiro, 2 fev. 1970, p. 10.

\section{Discos citados (ordem cronológica)}

SIMONAL, Wilson. Wilson Simonal tem algo mais. Rio de Janeiro, Odeon, 1963. LP.

SIMONAL, Wilson. A nova dimensão do samba. Rio de Janeiro, Odeon, 1964. LP. 
|82|

Wilson Simonal: vida e morte...

SIMONAL, Wilson. Alegria, alegria. Rio de Janeiro, EMI-Odeon, 1969. LP.

SIMONAL, Wilson. V Festival Internacional da Canção. Rede Globo: homenagem da Shell Brasil. Rio de Janeiro, EMI-Odeon, 1970. EP.

SIMONAL, Wilson. A Bossa e o balanço. São Paulo, Warner Music, 1994. CD. 